FONTES E ARQUIVOS 



\section{Índios vassalos versus Portugueses descansados - Liberdade, terra e trabalho na vila indígena de Benavente (capitania do Espírito Santo, 1795)}

\section{Vânia Maria Losada Moreira*}

Resumo: Requerimento encabeçado por vários índios da vila de Nova Benavente e endereçado à rainha D. Maria I, em 1795. Nele, denuncia-se esbulhos territoriais e indevidos procedimentos de extração do trabalho indígena na região. Para serem ouvidos em suas súplicas, os índios iniciaram uma verdadeira epopeia, em que dois procuradores índios dirigiram-se à Bahia e depois à Lisboa. Na corte, a rainha acatou as denúncias e mandou que os fatos fossem apurados e a "justiça distribuída" aos índios naquilo que fosse procedente. Em razão disso, foi instaurado um processo judicial na vila de Benavente e, dentre os muitos documentos anexados ao processo, encontra-se o requerimento transcrito e comentado no texto. Atualmente, o conjunto documental está reunido em um único processo depositado no Arquivo Histórico Ultramarino, em Lisboa.

Em 2001, John Manuel Monteiro publicou um balanço importante sobre o lugar ocupado pelos índios na historiografia relativa ao Brasil. Em relação à história colonial da América portuguesa, afirmou que um dos desafios era superar a carência de fontes primárias que trouxessem de modo mais explícito e direto as vozes indígenas, pois, como ele mesmo escreveu, a "ausência quase total de fontes textuais e iconográficas produzidas por escritores e artistas índios por si só impõe uma séria restrição aos historiadores." "Mas tanto para a história colonial, quanto para as demais temporalidade da experiência brasileira, Monteiro acrescentou: "o maior obstáculo impedindo o ingresso mais pleno de atores indígenas no palco da historiografia brasileira parece residir na resistência dos historiadores ao tema, considerado, desde há muito, como alçada exclusiva dos antropólogos.”2

* Universidade Federal Rural do Rio de Janeiro.

1 MONTEIRO, John Manuel. Tupis, tapuias e historiadores: estudos de História Indígena e do Indigenismo. Tese de livre docência. Unicamp, 2001, p. 2.

2 MONTEIRO. Tupis, Tupis, tapuias e historiadores, p.2. 
Interessar-se pelos índios e garimpar arquivos em busca deles e de suas vozes e testemunhos foi um desafio lançado pela prática e pela inteligência aguçada de John Monteiro, que muitos aceitaram com entusiasmo e dedicação. O documento que segue transcrito é um requerimento redigido em nome de mais de 40 índios, todos moradores da vila de índios de Nova de Benavente, na capitania do Espírito Santo, endereçado à rainha D. Maria I, em 17 de setembro de 1795. Não é possível saber se o texto foi escrito pelo próprio punhode um dos índios que também assinou o documento. Na documentação, aliás, os indícios são de que a carta teria sido "feita pela letra de um mulato de péssima conduta e chamado Antônio Alexandrino que vivia na dita vila de Benavente, e hoje é falecido". 3 Mas não restam dúvidas de que se trata de um testemunho de seus pontos de vista e de que, por traz das letras, estão vozes, esperanças e experiências indígenasda América portuguesa. A transcrição foi feita no bojo de minha própria investigação e nunca teve a pretensão de ser um genuíno exercício de paleografia. Por isso, foi vertida para o português atual, mas a pontuação, o uso de letras maiúsculas, bem como nomes e certas expressões de época ficaram de acordo com o texto original. A transcriçãopretende ser, portanto, fundamentalmente um guia facilitador da leitura do manuscrito original, pois meu principal objetivo é estimular o debate sobre as vozes e o protagonismo dos índios na história.

No requerimento, os índios denunciaram esbulhos territoriais e indevidos procedimentos de extração do trabalho indígena na região; e ambas as ilegalidades eram conduzidasamando do capitão-mor da capitania do Espírito Santo e de outras autoridade locais ou pelo menos debaixo das vistas deles. A rainha acatou as denúncias e mandou que os fatos fossem apurados e a "justiça distribuída"aos índios naquilo que fosse procedente. Em razão disso, foi instaurado um processo judicial na vila de Benavente e, dentre os muitos documentos anexados ao processo, encontra-se esse requerimento. Atualmente, o conjunto documental está reunido em um único processo depositado no Arquivo Histórico Ultramarino, em Lisboa. ${ }^{4}$

Por alvará de $1^{\circ}$ de janeiro de 1759, o aldeamento jesuítico de Nossa Senhora de Reritiba foi elevada à categoria de vila, recebendo o nome de vila Nova de Benavente. ${ }^{5}$ No entanto, somente em 14 de fevereiro 1761 a vila foi de fato instalada pelo ouvidor da capitania Francisco Salles Ribeiro, tendo por limites o Monte Agha, em Itapemirim, e a lagoa Mãi Bá, em Guarapari. ${ }^{6}$ Tudo isso estava de acordo com as ordens dadas por D. José I, com base na nova legislação pombalina, criada para reger os índios durante o seu governo. Em nome dos índios que residiam na vila recém-criadae de seus descendentes, $D$. José passou carta de sesmaria sobre seis léguas de terra, para suas lavouras e comércio.7 A extensão e limites da sesmaria dos índios coincidia com os limites e a extensão da própria vila de Nova Benavente ou, em outras palavras: as terras dos índios e as terras da vila formavam um único e só terreno, demarcado em nome dos índios e de seus sucessores.

Na década de 1790, quando eclodiu o conflito entre índios e portugueses em

3 AHU. ACL. CU 005-01. Cx 93, doc.18.227. Sobre o sentido negativo do termo "mulato", nesse período, cf. VIANA, Larissa. O idioma da mestiçagem. As irmandades de pardos na América portuguesa. Campinas-SP: Editora da Unicamp, 2007, p 37.

4 O processo inteiro está anexado a um ofício expedido por D. Fernando José de Portugal ao ministro D. Rodrigo de Souza Coutinho. Cf. AHU. ACL. CU 005-01. Cx 93, doc. 18.206-18.227.

5 DAEMON, Bazilio Carvalho. A província do Espírito-Santo. Sua descoberta, história chronologica, synopsis e estatística. Victoria: Typographia do Espírito-Santo, 1879, p. 165.

6 DAEMON. A província do Espírito-Santo, p. 170.

7 LEITE, Serafim. História da Companhia de Jesus no Brasil. Belo Horizonte: Itatiaia, 2006, T. 6, L. 2, p. 150. 
Benavente, a vila era a segunda mais populosa da capitania, ficando atrás apenas da vila de Vitória, que funcionava como cabeça de comarca e capital. Segundo as estimativas estatísticas da época, sua população era esmagadoramente indígena, pois contabilizava 3.119 índios e 102 escravos vivendo na vila em $1790 .{ }^{8} \mathrm{Nova} \mathrm{Be}-$ navente era, portanto, não apenas uma genuína vila de índios, mas igualmente a segunda maior e mais populosa vila da capitania do Espírito Santo. ${ }^{9}$ O conflito ganhou contornos políticos quando um grupo de moradores do termo de Iryry (ou Iriri), todos eles índios, sentiram-se lesados com que andavam fazendo certos "portugueses", tanto "pardos" quanto "brancos", contra seus direitos de posse e domínio sobre as terras que receberam D. José..$^{10}$ Imbuídos do desejo de defenderem seus modos de viver, seus valores e o que entendiam ser seus direitos e a verdade, eles resolveram lutar pelas terras que possuíam na condição de índios cristãos e vassalos da coroa portuguesa e pela liberdade que poderiam desfrutar nelas, dando início a uma tribulada epopeia que durou pelo menos três anos.

Acionaram, de início, o poder local, quando, em agosto de 1795, 15 índios apresentaram um requerimento ao senado da câmara da vila de Nova Benavente, em que denunciavam a invasão de suas terras por um homem chamado José da Silva Pereira.Pouco depois, em 21 de agosto de 1795, o ouvidor da comarca do Espírito Santo e conservador dos índios, José Pinto Ribeiro despachou ao diretor dos Índios, recomendando-lhe que verificasse com o juiz de medição de terras a situação dos índios, reafirmando que só podiam ser aforadas as terras "totalmente devolutas" para que os índios não fossem prejudicados em suas posses e domínio." Por razões não explicitadas na documentação que sobrou do caso, o mesmo ouvidor e conservador dos índios suspendeu o despacho dado anteriormente. Isso talvez explique porque os índios resolveram ir mais fundo na defesa de seus direitos e recorrer à "Soberana Rainha", dando àquestão contornos políticos e jurídicos mais largos e expressivos. Assim, em 17 de setembro de 1795, dois oficiais do Senado da Câmara da vila de Nova Benavente - i.e., um vereador e um juiz ordinário, ambos índios -, encabeçaram e assinaram o requerimento,juntamente com um terceiro índio não identificado como oficial da câmara. O requerimento era destinado à rainha $\mathrm{D}$. Maria I eainda estava subscrito nominalmente por outros 40 índios moradores da mesma vila.

No documento eles denunciavam a "ambição" dos "portugueses", tanto "pardos" quanto "brancos", que invadiam e tomavam as terras dos índios à mando do escrivão e diretor dos Índios da vila de Benavente, Domingos Pereira Portela. Também delatavam o "despotismo" do capitão-mor e governador da capitania que, além de querer aforar as terras dos índios "aos moradores do Rio Caraype, freguesia e outros lugares", Ihes impunha uma espécie de cativeiro, chamandoos de "cabocollos" e forçando-os a trabalhar, sem remuneração, em inúmeros

8 MOREIRA, Vânia Maria Losada. "Nós índios, índios nós senhores de nossas ações... Direito de domínio dos índios e cristandade em conflito (vila de Nova Benavente, capitania do Espírito Santo, 1795-1798)". In: MOTTA, Márcia; SERRÃO, José Vicente; MACHADO, Marina (orgs.). Em terras lusas: conflitos e fronteiras no império português. Vinhedo: Editora Horizonte, 2013.

9 Sobre a vida dos índios durante o Diretório pombalino, cf., dentre outros autores: LOPES, Fátima Martins. Em nome da liberdade: as vilas de índios do Rio Grande do Norte sob o Diretório pombalino no século XVIII. Recife: Universidade Federal de Pernambuco. Tese de Doutorado, 2005. SOMMER, Barbara Ann. Negotiated Settlements: Native Amazonians and Portuguese Policy in Pará, Brazil, 1758-1798. NovoMexico: Universityof New Mexico, 2000. DOMINGUES, Ângela. Quando os índios eram vassalos: colonização e relações de poder no Norte do Brasil, na segunda metade do século XVIII. Lisboa: Comissão Nacional para as Comemorações dos Descobrimentos Portugueses, 2000.

10 ACL.CU.005-01, Cx. 93, doc. 18.226

11 ACL.CU.005-01, CX. 93, doc. 18.226 
serviços para ele e seus apadrinhados. De acordo com os índios, os "Portugueses descansados, sem trabalho algum [ficam] somente cuidando e indagarem modos de porem aos Índios em pobreza...". ${ }^{12}$

Pelo número de autoridades citadas e envolvidas nas denúncias feitas pelos índios pode-se aquilatar o tamanho da disputa social, política e econômica em que eles se meteram para manter o domínio sobre suas terras e livrarem-se das tentativas dosportugueses de reduzi-los ao cativeiro. Mas, sem apoio das autoridades locais e até mesmo em aberto conflito com elas, os índios de Benavente resolveram enviardois procuradores à Bahia, com o fito de defender seus interesses, pois, então,era a capitania subordinada ao governo da Bahia. Da primeira ida dos índios de Benavente à Bahia sobrou como testemunho um ofício, endereçado ao ouvidor da comarca do Espírito Santo, datado de 20 de dezembro de 1795, em que se manda tomar providências em relação às reclamações dos índios. Mas o ofício enviado pelo governo da Bahia ao corregedor do Espírito Santonão surtiu os efeitos esperados. Isso conduziu os índios ainda mais longe em busca de justiça: enviaram os dois representantes à Corte, em Lisboa, para promover os interesses deles junto à rainha.

Sobre a partida dos procuradores dos índios para Lisboa não é possível saber muito. Seus nomes eram Antonio da Silva e Francisco Dias; eram irmãos e começaram a viver uma perigosa aventura ao assumirem a posição de "procuradores" e defensores dos direitos dos índios de Benavente, pois sofrerem reveses e perseguições. O primeiro problema ocorreu na viagem para Lisboa, quando ambos acabaram presos para a equipagem de uma fragata chamada Tritão. Ser preso para a equipagem de um navio é um modo mais suave de dizer que ambos foram forçados a trabalhar compulsoriamente na fragata. Apesar de estarem em condição tão desfavorável, conseguiram chegar à Lisboa e apresentaram outro requerimento à rainha, em quesolicitavam que ela se dignasse a "condoer-se da opressão que fazem aos suplicantes e ordenar que não sejam expulsos das ditas suas terras, porque presentemente já não são mais gentios, mas sim observadores da verdadeira religião da Igreja Romana". ${ }^{3}$

Um dos aspectos mais interessantes da pequena petição assinada em cruz pelos procuradores Antonio da Silva e Francisco Dias é justamente o de assumirem, com vigor, a condição e a identidade de índios cristãos e vassalos da rainha, em oposição aos "gentios", i.e., àqueles índios não avassalados pela coroa portuguesa e que viviam nos sertões e florestas do Brasil. D. Maria I era tida pelos portugueses como uma soberana piedosa e, de fato, apiedou-se dos índios de Benavente, pois terminou acolhendo a denúncia deles, ordenando ao secretario de Estado dos Negócios da Marinha e Domínios Ultramarinos, D. Rodrigo de Souza Coutinho, que tomasse as providências necessárias sobre o assunto.

Na sequência, ocorreu um efeito cascata: D. Rodrigo escreveu a D. Fernando José de Portugal, governador da Bahia, à quem a capitania do Espírito Santo estava subordinada, cobrando solução e justiça em relação ao pleitos dos índios. Corria, então, o ano de 1797. D. Fernando enviou carta à José Pinto Ribeiro, ouvidor e corregedor da comarca do Espírito Santo, orientando-o que tomasse todas as providências em relação ao assunto: "[...] ordeno a vossa mercê", escreveu D. Fernando ao ouvidor do Espírito Santo, "que com toda brevidade me informe o sobredito requerimento [que os índios levaram à presença da rainha] fazendo

12 ACL.CU.005-01, Cx. 93, doc. 18.226.

13 ACL.CU.005-01, Cx. 93, doc. 18.226. 
entretanto pronta e exata justiça aos referidos Índios, nas pretensões que forem justas." 14

Nesse ínterim, Antonio da Silva e Francisco Dias terminaram livrando-se do trabalho forçado na fragata Tritão e retornaram ao Brasil, trazendo com eles pelos menos duas cartas importantíssimas para a causa que defendiam. A primeira era da própria rainha. Essa carta está desaparecida, mas é D. Fernando José de Portugal, governador da Bahia, quem dá testemunho de tê-la visto, quando os irmãos e procuradores dos índios, de regresso de Lisboa, passaram pela Bahia e lhe apresentaram a tal carta de D. Maria I. A segunda era assinada por D. Rodrigo de Sousa Coutinho, endereçada a D. Fernando José de Portugal. Ao que tudo indica, tratavase uma cópia da carta enviada a D. Fernando pelo Secretário, que consta no processo.

De regresso à vila Nova de Benavente, os irmãos Antonio da Silva e Francisco Dias causaram alvoroço entre os moradores locais. Segundo a opinião das autoridades locais, a chegada deles gerou grande "desordem" entre os índios da vila, mas, a partir da documentação disponível, não está claro o que concretamente fizeram os índios quando receberam a boa nova de que a rainha $\mathrm{D}$. Maria e seu secretário de Estado, D. Rodrigo de Souza Coutinho, haviam acolhido asdenúncias feitas por eles, ordenando, além disso, que a justiça fosse feita na vila. É possível, contudo, imaginar os desdobramentos da notícia, pois certamente os índios se sentiram muito mais animados e amparados para continuarem lutando por seus direitos. O rebuliço foi grande também entre os "portugueses". Testemunho disso são três cartas escritas pelo escrivão e diretor dos Índios da vila de Benavente ao ouvidor e corregedor da comarca do Espírito Santo, informando sobre as "desordens" provocadas pelos índios na vila de Benavente. O próprio ouvidor, pouco depois, escreveu a D. Fernando, pondo-o a par dos acontecimentos na vila. Mas as três cartas, embora mencionadas nos autos, não estão anexadas à documentação do processo.

É nesse contexto, contudo, em que os índios estavam agitados e de posse de duas cartas que lhes reconheciam um lugar de direito na monarquia portuguesa, que, em fevereiro de 1798, o ouvidor José Pinto Ribeiro chegou à vila de Nova Benavente, para dar cumprimento às ordens recebidas. Acompanhado de um escrivão vindo da Bahia, o ouvidor deu início às investigações para "distribuir justiça", tal como ordenava a rainha. A Justiça na capitania era bastante precária e simplificada: a principal autoridade judiciária era o próprio ouvidor, enquanto nas vilas atuavam os juízes ordinários. Chegando em Benavente, o ouvidor inquiriu a Câmara sobre a representação dos índios, juntou vários documentos sobre os aforamentos e sobre os dízimos pagos pelos índios e por outros moradores da vila e recolheu o nome dos indivíduos que exerceram os cargos de juízes ordinários, vereadores e procurador da câmara no ano de 1795, quando a representação à rainha foi escrita. Além disso, para melhor apurar os fatos, durante dois dias tomou o depoimento de 22 testemunhas. Dentre elas, 18 eram índios e os demais homens pardos ou brancos casados com índias. Os depoimentos foram transcritos pelo escrivão da Ouvidoria Geral da Correição da Bahia e anexados ao processo.

O desenlace do episódio se deu em 1798: o ouvidor proferiu a sentença sobre o caso e, no ofício que mandou ao governador da Bahia, datado de 4 de abril de 1798 , resumiu os procedimentos realizados e concluiu "ser a representação feita a Sua Majestade afetada, e urdida pelo orgulho dos Índios, Francisco Dias e

14 AHU. ACL. CU. 005-01. Cx. 93, doc.18.220. 
Antônio José Lopes, e também um chamado Antônio da Silva, e feita pela letra de um mulato de péssima conduta e chamado Antônio Alexandrino que vivia na dita vila de Benavente, e hoje é falecido."15 Para ele, os índios não tinham razão nas queixas que apresentaram à rainha, pois só recentemente três "brancos" estavam inquietando-os em suas terras. Mas, para realizar "exata e pronta justiça aos Índios nas pretensões que fossem justas", tal como tinha sido ordenado pela rainha, notificou aos três brancos que não mais incomodassem os índios, cominando pena em caso de reincidência no erro. ${ }^{16}$

No mesmo mês de abril de 1798, D. Fernando José de Portugal recebeu o processo e encaminhou-o a D. Rodrigo de Souza Coutinho, referendando a sentença do ouvidor da comarca do Espírito Santo sobre o conflito de terras na vila de Benavente e sobre a representação que os índios fizeram à rainha. É esse conjunto de documentos que estão reunidos e depositados no Arquivo Histórico UItramarino, em Lisboa. Sobre os irmãos e procuradores dos índios, Antonio da Silva e Francisco Dias, ainda se sabe que terminaram fugindo da vila, levando consigo mulher e filhos, certamente para escapar de represálias e perseguições. Dessa luta política e epopeia vivida pelos índios ficaram marcas na memória social local, pois, em 1818, ao passar pela vila, Saint-Hilaire percebeu entre os índios um profundo descrédito em relação à eficácia da Justiça: "Quando o índio pede justiça ao português, como poderá obtê-la? É aos amigos e patrícios de seus adversários que ele é obrigado dirigir-se...". ${ }^{17}$

Nesse breve comentário a esse valioso corpo documental, não é possível explorar as muitas possibilidades de análise. Ponho em relevo, contudo, que se trata de uma fonte onde as vozes indígenas estão mais audíveis, bem como o sentido profundo de seu protagonismo histórico em defesa de seus modos de vida, famílias e direitos de liberdade, domínio e posse de terras. Trata-se, além disso, de um corpo documental que dá testemunho sobre o lugar político e jurídico do "índio colonia”?, i.e., vassalo da monarquia, pois foi como vassalos que eles ocuparam os cargos políticos do povoado e buscaram Justiça junto à "soberana rainha", em Lisboa.

Para concluir, cito um provérbio que talvez resuma bem o significado dessa epopeia para os índios, seus descendentes e todos aqueles que apreciam a história e a historiografia feita "de baixo para cima": Palma sub pondere crescit. ${ }^{18}$

15 AHU. ACL. CU 005-01. Cx 93, doc.18.227.

16 AHU. ACL. CU 005-01. Cx 93, doc.18.221.

17 SAINT-HILAIRE, Auguste de. Viagem ao Espírito Santo e Rio Doce. Belo Horizonte: Itatiaia, 1974, p. 32.

18 "Os homens do deserto contam que a palmeira cresce até mesmo quando deve se curvar sob o vento e as areias, donde o provérbio "Palma sub pondere crescit” (a palmeira cresce sob o peso): as dificuldades só fazem crescer as forças dos que as enfrentam." (f. LELOUP, Jean-Yves. O ícone. Uma escola do olhar. São Paulo: Editora Unesp, 2006, p. 67. 


\section{Transcrição}

Referência: Arquivo Histórico Ultramarino - AHU. ACL.CU.005-01, Cx. 93, doc. 18.226.

\section{Soberana Senhora,}

Aos Reais pés de Vossa Majestade se prostram os Índios e mais moradores da Vila Nova de Benavente da Comarca do Espírito Santo pedindo a Vossa Real Majestade que como mãe comum tenha por bem pôr os seus reais olhos nestes seus pobres vassalos, pois esperam que Vossa Real Majestade os favoreça e lhes distribua justiça na forma que os vassalos de Vossa Real Majestade Ihes requerem que é o seguinte: somos moradores no termo da mesma Vila de Benavente, dentro dos marcos da mesma Vila, desde o lugar chamado Maymba, em que se compreende desde o mesmo lugar até o mesmo do Iryry, mais de sete léguas de terra, e toda esta se acha cheia de sítios em que moram mais de quatrocentas pessoas, tanto casados, com casas de vivenda, e famílias, agriculturas, plantações de legumes, serrarias, de que pagam de tudo direito a Vossa Real Majestade e, juntamente muitas pessoas solteiras que nas mesmas terras trabalham e pagam também os mesmos direitos naqueles lugares, e dentro das ditas sete léguas que de uma parte, a outra tem de circunferência, estão de posse os ditos moradores pacificamente há mais de quarenta anos por si e seus antes possuidores, sem serem estorvados nem impedidos de portugueses alguns; porque naquele tempo se não consentia ali se aforarem as terras dos Índios, conforme os Decretos das Majestades, em que mandam que terras de Índios se não aforem a Portugueses, mas antes estes Decretos se achavam cumpridos pelo Ministro Paschoal Ferreira Deveras, que foi o primeiro de vara Branca que veio ao Brasil; depois o Dr. Matheus Nunes José e Macedo, [mudança de página] Macedo e o Dr. Bernardino Falcão de Gouveia, Francisco Salles Ribeiro, que foi o que erigiu a mesma Vila de Benavente, o Dr. José Ribeiro Guimarães e Ataíde, Manoel Carlos da Silva e Gusmão. e outros Ouvidores, senhores destes, cumprindo em tudo os ditos decretos, e juntamente muitas condições que se acham no Livro do Tombo que fez o primeiro Ministro Paschoal Ferreira Deveras, há mais de sessenta anos por ser o primeiro criador da Comarca mandando observar tanto na dita Vila de Benavente [e na ?] então Aldeiade Reis Magos, que agora também é Vila, por ereção do mesmo Dr. Salles, por ordem que teve da Majestade do Sr. Rei Dom Joam Quinto de gloriosa memória, cujos preceitos, ainda até o presente se está observando na dita Nova Almeida; em se não consentir Portugueses aforados com sítios, e casas, engenhos nas terras dos Índios daquela Vila, exceto se algum se quiser casar com Nacional da terra, e na mesma Benavente assim se observou até o tempo que foi Ouvidor o mencionado Ministro Athayde e agora se tem introduzido tanta [ambição ?] nos Portugueses, tanto brancos, e pardos e de outras nações por lhes haverem aforado as Câmaras da mesma Benavente terras por mandado e conselho de um Domingos Pereira Portela, que é Escrivão e Diretor dos Índios, por consentimento outrossim do ouvidor que agora serve chamado José Pinto Ribeiro que tem os mesmos Portugueses tomado toda a terra dos ditos Índios, e não tem estes onde mais possam trabalhar para sustento das suas famílias, por os ditos Portugueses Ihes terem tomado com medições e rumos falsos e com dolo e malícia fincando marcos e entrando por partes que impedem os Índios a não prosseguirem [mudança de página] 
prosseguirem adiante por estarem impedidos dos ditos Portugueses, por estarem estes estabelecendo sítios para erigirem fazendas, engenhos de fabricar açúcar o que nunca se viu nem praticou naqueles lugares só a fim de quererem perturbar os ditos Índios que há tantos anos estão na sua tranquilidade e sossego, como também estamos expostos para tudo quanto é do serviço de Vossa Real Majestade, já serrando madeiras pelos sertões para carretas das pessoas da guarnição da vila da Vitória e suas Fortalezas, prontos para os destacamentos de um sertão chamado Icoanha e Santa Maria, expostos a morrerem às mãos do Gentio Bárbaro e outros mais ónus que a cada instante se estão demovendo aos ditos Índios que largam suas casas mulheres e filhos para tudo cumprirem exatamente ainda a poder de despesas dos ditos Índios e os Portugueses descansados, sem trabalho algum somente cuidando e indagarem modos de porem aos Índios em pobreza, tanto assim que os pobres alguma camisa que tem, a levam para os ditos destacamentos e não são munidos de outras e os mantimentos muito diminutos que não chegam para sustento dos suplicantes e das suas famílias; e quanto também não podem resistir com tanto trabalho, pois parece justo e de razão, um corpo, não padecem duas penas. $E$ todos os que aqui presentes por nossos nomes, nos pomos aos venerandos e Reais Pés de Vossa Majestade, pedindo nos ampare e patrocine, e nos dê o seu Real auxílio; que não possam os Portugueses nos tomar as nossas terras, e nem os Magistrados da Comarca da Capitania mandar que se lhas entregue aos Portugueses, pois os Índios tem afirmado que haverá na dita Vila de Benavente, desde as compreensões dos ditos marcos até o fim deles, que é do mencionado Mayambá, até o referido Iriry, onde todos estão compreensíveis e dentro dos mencionados marcos, como são os queixosos aqui nomeados Francisco da Silva, Manoel Pereira da Paixam, Silvestre Dias, [mudança de página] Dias Antonio da Silva, Domingos Carneiro Gomes, Joam Cardoso, Francisco Mimoso, Antonio Estevam , Joam Francisco Reges, Francisco Xavier, José Francisco Torres, Joam Viegas, Antonio Viegas, Joao Ignacio, Antonio Gomes Portela, o Capitão Bruno Lopes de Oliveira, João Manuel, Ignacio Viegas, Inocencio Antonio, Antonio Antonio Freire, Gonçalo Vaz, Carneiro, Ignacio de Abreu, Fabiano de Sousa, João Pires, Antonio Pires, João Gonçalves, João da Silva, Domiciano Correia., Joan de Sousa, Fernando dos Reis, Silvestre dos Santos, casado, José Ramos, casado, João de Almeida, casado, Gaspar Borja casado, Luis Pereira casado, João da Cruz casado, Lorenço da Silva, também casado, Luciano Leitão, casado, Manoel Luís, Francisco da Silva, todos casados e moradores, mais outros moradores que aqui se não nomeiam por morarem muito distantes da circunferências das ditas léguas que se compreendem de marco a marco, eos mesmos se prostram também como voz do Povo e o costume antigo também faz Lei: os Jesuítas que criaram as ditas aldeias que agora são vilas, nunca consentiram Portugueses alguns nelas aforados e nem dadas as ditas terras por sesmaria como ainda se pratica na Nova Almeida.

Ainda que o Capitão Mor e Governador da dita Capitania na dita vila querendo espoticamente [despoticamente?] querer aforar terras aos moradores do Rio Carahyipe e da Freguesia e de outros lugares por empenhos que tinha por entrepostas pessoas porém nunca pode conseguir, ainda se está observando até o presente. Nestes termos recorrem os Suplicantes miseráveis muito pobres e falando com todo muito devido respeito, e toda devida submissão; a Vossa Soberana Majestade, tenha por bem de conceder aos seus muito em tudoleais vassalos, o que pedem neste memorial, pois isto é sumamente verdade, para o que vão assinados o Juiz Ordinário Antônio da Cruz[mudança de página]Telese o Procurador do Conselho Ignnacio Lemos. Tenho mais que requerer a Vossa Real Majestade que 
o Capitão Mor e Governador da capitania mandam buscarmos a nós Índios, Índios nós senhores de nossas ações, e nascermos livres de ônus de cativeiro para nos mandar trabalhar em partes imundas ou onde lhes parece, e por petitórios até de seus amigos para fazer o mesmo nas suas fazendas e o pagamento que dão aos ditos Índios quando lhe pedem os jornais é chamar cabocollo, pancadas e destacamento e serras para a sua conveniência.

Vossa Majestade a tudo isto atenda e defira como Mãe aos vossos pobres filhos com Piedade, e retidão de Justiça. 17 de setembro de 1795. Juiz Ordinário [assinado com uma cruz] Marcelino Fernandes Lobato; [assinado]do vereador Antônio Fernandes [assinado] José Lobato Gonçalves

Vossa Real Majestade nos atenda

\section{Muito Soberana Senhora}

Para mais prova do que expomos a Vossa Real Majestade apresentamos o requerimento junto para Vossa Real Majestade ver o dolo e malícia do Escrivão Diretor da mesma Vila de Benavente, por ser inimigo capital dos Índios, e não quis dar cumprimento ao despacho Ouvidor da Comarca do Espírito Santo que junto se acha [mudança de página] que junto oferece porque vive coligado com um Dom Domingos Vaz que servia de Juiz Ordinário que não fosse sem os Índios depositarem quinze patacas metade para o Escrivão e metade para o Juiz. O mesmo conselho deram Francisco Xavier Pinto Saraiva, Mariano Pereira, José da Silva Pereira, Luis Antonio de Oliveira, por todos estes serem opostos os Índios a terem lavouras no dito lugar. 
